\title{
Pharmacokinetic profile of amodiaquine and its active metabolite desethylamodiaquine in Ghanaian patients with uncomplicated falciparum malaria
}

Thomas A. Anyorigiya1,2,3, Sandra Castel1', Katya Mauff', Frank Atuguba ${ }^{3,5}$, Bernhards Ogutu $^{6}$, Abraham Oduro $^{3}$, David Dosoo ${ }^{7}$, Kwaku-Poku Asante 7 , Seth Owusu-Agyei ${ }^{8}$, Alexander Dodoo ${ }^{9}$, Abraham Hodgson 3,10, Fred Binka ${ }^{8}$, Lesley J. Workman ${ }^{1,2}$, Elizabeth N. Allen ${ }^{1,2}$, Paolo Denti ${ }^{1,2}$, Lubbe Wiesner ${ }^{1,2}$ and Karen I. Barnes ${ }^{1,2^{*}}$ (D)

\begin{abstract}
Background: Accurate measurement of anti-malarial drug concentrations in therapeutic efficacy studies is essential to distinguish between inadequate drug exposure and anti-malarial drug resistance, and to inform optimal antimalarial dosing in key target population groups.

Methods: A sensitive and selective LC-MS/MS method was developed and validated for the simultaneous determination of amodiaquine and its active metabolite, desethylamodiaquine, and used to describe their pharmacokinetic parameters in Ghanaian patients with uncomplicated falciparum malaria treated with the fixed-dose combination, artesunate-amodiaquine.
\end{abstract}

Results: The day-28 genotype-adjusted adequate clinical and parasitological response rate in 308 patients studied was $>97 \%$ by both intention-to-treat and per-protocol analysis. After excluding 64 patients with quantifiable amodiaquine concentrations pre-treatment and 17 with too few quantifiable concentrations, the pharmacokinetic analysis included 227 patients ( 9 infants, 127 aged $1-4$ years, 91 aged $\geq 5$ years). Increased median day- 3 amodiaquine concentrations were associated with a lower risk of treatment failure [HR 0.87 ( $95 \% \mathrm{Cl} 0.78-0.98), p=0.021$ ]. Amodiaquine exposure (median $\mathrm{AUC}_{0-\infty}$ ) was significantly higher in infants $(4201 \mathrm{ng} \mathrm{h} / \mathrm{mL}$ ) and children aged 1-5 years (1994 $\mathrm{ng} \mathrm{h} /$ $\mathrm{mL}$ ) compared to older children and adults ( $875 \mathrm{ng} \mathrm{h} / \mathrm{mL}, \mathrm{p}=0.001$ ), even though infants received a lower $\mathrm{mg} / \mathrm{kg}$ amodiaquine dose (median 25.3 versus $33.8 \mathrm{mg} / \mathrm{kg}$ in older patients). Desethylamodiaquine $\mathrm{AUC}_{0-\infty}$ was not significantly associated with age. No significant safety concerns were identified.

Conclusions: Efficacy of artesunate-amodiaquine at currently recommended dosage regimens was high across all age groups. Reassuringly, amodiaquine and desethylamodiaquine exposure was not reduced in underweight-for-age young children or those with high parasitaemia, two of the most vulnerable target populations. A larger pharmacokinetic study with close monitoring of safety, including full blood counts and liver function tests, is needed to confirm the higher amodiaquine exposure in infants, understand any safety implications and assess whether dose optimization in this vulnerable, understudied population is needed.

\footnotetext{
*Correspondence: karen.barnes@uct.ac.za

1 Division of Clinical Pharmacology, Department of Medicine, University of Cape Town, Cape Town, South Africa
}

Full list of author information is available at the end of the article

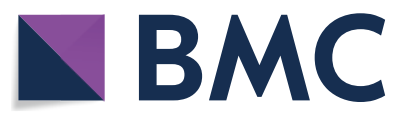

(c) The Author(s) 2021, corrected publication 2021. This article is licensed under a Creative Commons Attribution 4.0 International License, which permits use, sharing, adaptation, distribution and reproduction in any medium or format, as long as you give appropriate credit to the original author(s) and the source, provide a link to the Creative Commons licence, and indicate if changes were made. The images or other third party material in this article are included in the article's Creative Commons licence, unless indicated otherwise in a credit line to the material. If material is not included in the article's Creative Commons licence and your intended use is not permitted by statutory regulation or exceeds the permitted use, you will need to obtain permission directly from the copyright holder. To view a copy of this licence, visit http://creativecommons.org/licenses/by/4.0/. The Creative Commons Public Domain Dedication waiver (http://creativeco mmons.org/publicdomain/zero/1.0/) applies to the data made available in this article, unless otherwise stated in a credit line to the data. 
Keywords: Amodiaquine, Artesunate, Fixed-dose combination, Pharmacokinetics, P. falciparum malaria, Ghana, Infants, Young children, Underweight-for-age, Parasite density

\section{Background}

Since 2000, there have been dramatic increases in political and financial commitments towards efforts to control malaria, with widespread deployment of artemisinin-based combination therapy (ACT) as first-line treatment of uncomplicated Plasmodium falciparum malaria, which has contributed to significant decreases in the malaria burden $[1,2]$. Artesunate plus amodiaquine (ASAQ) is one of five artemisinin-based combinations currently recommended by the World Health Organization (WHO) [3] and was introduced as firstline treatment in Ghana in 2005 [4]. At that time, the therapeutic efficacy of ASAQ was $100 \%$ in children under five followed up for 28 days [5]. Subsequently, cure rates ranging from 80 to $100 \%$ were found in Ghanaian children aged 6 months to 10 years, the age group with the highest malaria burden [6-10].

Effective malaria treatment requires that the frequency and dose of anti-malarial drugs is adequate to provide sufficient drug concentrations over time to kill all parasites in all key target populations [11]. Sub-therapeutic drug exposures contribute to poorer treatment responses and may fuel the spread of anti-malarial resistance [12]. In therapeutic efficacy studies, inadequate drug exposure may be misinterpreted as parasite resistance unless drug concentrations are accurately measured [3]. Despite extensive use of amodiaquine for many years, previously as a monotherapy and currently in combination with artesunate for the treatment of uncomplicated falciparum malaria $[13,14]$ and in combination with sulfadoxine-pyrimethamine for Seasonal Malaria Chemoprevention $[15,16]$, pharmacokinetic data are limited particularly for the parent compound amodiaquine and in key target populations such as very young and malnourished children and patients with uncomplicated hyperparasitaemia [17-23].

Drug concentrations are usually measured in plasma, but collection of plasma samples is less suitable for field studies [24]. As amodiaquine and desethylamodiaquine accumulate in white blood cells [24-26] and it is the red blood cells that are parasitized, concentrations of amodiaquine and desethylamodiaquine in whole blood may reflect the concentrations acting on the malaria parasites more accurately than plasma concentrations. Previously described methods for the simultaneous determination of amodiaquine and desethylamodiaquine concentrations required relatively large sample volumes $(0.1-1 \mathrm{~mL})$ that are not ideal for repeated sampling in young children [26-29].

This study aimed to characterize the pharmacokinetic and pharmacodynamic (PK/PD) profile of amodiaquine when given with artesunate as a fixed-dose combination to treat uncomplicated $P$. falciparum malaria in non-pregnant patients of all ages, including infants, malnourished young children and those with a high parasitaemia. This required the development and validation of a whole blood assay using small blood volumes, in order to ensure its feasibility for use in routine therapeutic efficacy studies.

\section{Methods \\ Study design and participants}

The study was conducted in Kassena-Nankana and Kintampo districts in Ghana, as a pharmacokinetic substudy of the INDEPTH Effectiveness and Safety Studies (INESS) of the therapeutic efficacy of fixed-dose artesunate-amodiaquine for the treatment of uncomplicated falciparum malaria. The Kassena-Nankana district is in northern Ghana, while the Kintampo district is in central Ghana, with a distance of about $400 \mathrm{~km}$ between the study sites.

Non-pregnant patients aged $>2$ months, weighing $>4.5 \mathrm{~kg}$ with $P$. falciparum mono-infection of 1000-200,000 parasites $/ \mu \mathrm{L}$ and fever (axillary temperature $\geq 37.5{ }^{\circ} \mathrm{C}$ or history of fever within $24 \mathrm{~h}$ ), willing to comply with the study procedures and with written informed consent or consent/assent, were included in the study at both Kassena-Nankana (Navrongo) and Kintampo sites between August 2011 to February 2012. To achieve the required sample size data collection continued in the Navrongo site only from July 2012 to January 2013. Those who had taken medication within the previous two weeks with known anti-malarial effects, potential interactions with amodiaquine/desethylamodiaquine pharmacokinetics or any artesunate-amodiaquine contra-indications were excluded.

\section{Study procedures}

Patients were given a fixed-dose combination of artesunate-amodiaquine (Coarsucam ${ }^{\circledR} / \mathrm{ASAQ}$ Winthrop; Sanofi-Aventis, Maphar Laboratories, Morocco) with water based on WHO recommended dosage regimens by body weight to achieve an artesunate target of $4 \mathrm{mg} / \mathrm{kg}$ 
body weight (range 2 to $10 \mathrm{mg} / \mathrm{kg}$ ) and amodiaquine target of $10 \mathrm{mg} / \mathrm{kg}$ body weight of amodiaquine base (range 7.5 to $15 \mathrm{mg} / \mathrm{kg}$ ) once daily for 3 days [3]. All patients were followed up at the Navrongo site according to the WHO protocol [30], with slight modifications in Kintampo where follow up was on days 2, 7, 14 and 28.

The exact time of each observed dose was recorded. Patients were observed for at least $30 \mathrm{~min}$ after treatment; if vomiting occurred within $30 \mathrm{~min}$, the full dose was repeated. Patients who vomited more than once were excluded and referred for appropriate hospital management. Treatment efficacy outcomes were classified as per 2009 WHO recommended methods [30]. Parasite identification and density were assessed on thin and thick blood smears by at least two independent microscopists, assuming a WBC count of $8000 / \mu \mathrm{L}$; at least 100 high power fields were read before declaring a slide negative [30]. Plasmodium falciparum deoxyribonucleic acid (DNA) was extracted from dried filter paper blood spots using a modified Chelex method, as described previously [31]. The three highly polymorphic P. falciparum antigens, MSP-1, MSP-2 and GLURP were used in the analysis to differentiate recrudescences from new infections [32]. To increase sensitivity, the PCR analysis of each gene involved 2 rounds of amplification with nested primers used in the second round. Primers and amplification conditions used were adapted from Ranford-Cartwright [33]. Parasite recrudescence was defined as the presence of identical PCR products in the samples from day 0 and the day of parasite recurrence (day X). Such recrudescences were further classified based on published criteria [32, 33].

An adverse event was defined as a new symptom or sign that developed post treatment or the exacerbation of a symptom or sign present at baseline. Treatment safety was assessed based on clinical signs and symptoms at each scheduled visit and on any unscheduled visit and by haemoglobin assessments on days 0 , (2), 7 , 14 and 28. Haemoglobin concentrations were determined in Navrongo on days $0,7,14$ and 28 using Hemocue Hb201 + photometers $^{\circledR}$ (HemoCue AB, SE-262 23 Ängelholm, Sweden) and in Kintampo on days 0, 2 and 28 using ABX Micros 60-OT haematology analyzer (HORIBA Ltd, France). No additional laboratory safety tests were performed.

\section{Amodiaquine and desethylamodiaquine quantification} Pharmacokinetic samples were placed in a sample storage boxes and stored at minus $70{ }^{\circ} \mathrm{C}$ at each site until shipment on dry ice to the analytical laboratory. Blood concentrations of amodiaquine and desethylamodiaquine were recovered from $20 \mu \mathrm{L}$ capillary whole blood samples collected into labeled lithium heparin tubes on all visits according to the same study SOP used at both sites based on WHO recommended methods [24, 30]. Pharmacokinetic blood samples were collected prior to artesunateamodiaquine administration on Days 0,1 , and 2. Whole blood concentrations were measured within 6 months of sample collection using a liquid chromatography tandem mass spectrometry assay developed and validated [34] in the Division of Clinical Pharmacology at the University of Cape Town. The assay consisted of a liquid-liquid extraction, followed by high performance liquid chromatography with tandem mass spectrometry detection. The combined accuracy (\%Nom) and precision (\%CV) statistics of the quality controls of amodiaquine and desethylamodiaquine during validation were between $93.9 \%$ and $108.3 \%$, and $3.2 \%$ and $5.8 \%$, respectively. (See Additional file 1 for further assay method details).

\section{Statistical analysis}

The sample size was calculated to compare the exposure of desethylamodiaquine in malaria patients who achieved adequate clinical and parasitological response and those who failed treatment. At an alpha value of 0.05 , a power of 0.80 and a cure rate of $92.5 \%$, a sample size per site of 119 was estimated. Assuming a 10\% loss to follow up, a total of 300 patients were targeted to be enrolled from the two sites in order to allow also for the comparison of exposure between similar numbers of patients under 5 years with older children and adults.

Efficacy outcome analysis was carried out using both intention-to-treat (ITT) and per protocol (PP) methods [30]. In line with the burden of disease in areas of high malaria transmission [35], age was categorized into infants ( $<1$ year), young children (aged $1-4$ years), and older children and adults ( $\geq 5$ years), after testing for any statistically significant differences between older children and adults. Data with skewed distributions such as parasite densities were log transformed before being compared using the normal approximation, one-way analysis of variance (ANOVA) with Bonferroni correction for multiple comparisons. The weightfor-age z-scores were calculated according to the WHO growth reference for children $\leq 5$ years [36].

\section{Pharmacokinetic analysis}

Pharmacokinetic parameters of amodiaquine and desethylamodiaquine were determined by a non-compartmental analysis using Stata v15 (StataCorp, Texas, USA). Patients who received treatment with any antimalarials (including amodiaquine) within two weeks prior to enrolment, were excluded from the study. Therefore, even if prior anti-malarial treatment was not self-reported, patients with quantifiable amodiaquine concentrations prior to dosing were deemed 
to have had recent anti-malarial treatment and were excluded from analysis. Patients with pre-dose quantifiable desethylamodiaquine concentrations, but with corresponding amodiaquine concentrations below the limit of quantification were however included in the analysis as this was interpreted as amodiaquine treatment given $>2$ weeks ago. Biologically implausible individual concentrations were also excluded from the analysis. A drug concentration was considered biologically implausible if, in the absorption phase or near the $C_{\max }$, it was $\geq 25 \%$ higher or lower than the 2 measured concentrations at adjacent sampling times or if, once in the terminal elimination phase, there was $a \geq 50 \%$ rise or fall relative to the two adjacent sampling times or the concentration increased after two successive lower concentrations.

The area under the concentration-time curve to infinity, $\mathrm{AUC}_{0-\infty}$ was estimated using the trapezoidal rule with exponential fit. At least 3 data points were required for the estimation of $\mathrm{AUC}_{0-\infty}$ and the terminal elimination rate constant $\left(\mathrm{k}_{\mathrm{e}}\right)$. The terminal elimination half-life was calculated as $\ln (2) / k_{\mathrm{e}}$. The maximum observed amodiaquine and desethylamodiaquine concentration $\left(\mathrm{C}_{\max }\right)$ and the first time of their occurrence $\left(\mathrm{T}_{\max }\right)$ were obtained directly from the observed concentration-time data. The apparent clearance $(\mathrm{CL} / \mathrm{F})$ and volume of distribution $(\mathrm{Vd} / \mathrm{F})$ were calculated as Total Dose/AUC ${ }_{0-\infty}$ and Apparent Clearance $/ \mathrm{k}_{\mathrm{e}}$, respectively, with $\mathrm{F}$ for bioavailability. For determining median amodiaquine and desethylamodiaquine concentrations at each time point, concentrations below the limit of quantification (BLQ) were set to half the lower limits of quantification i.e. $0.3905 \mathrm{ng} / \mathrm{mL}$ for amodiaquine and $1.955 \mathrm{ng} / \mathrm{mL}$ for desethylamodiaquine. All BLQ values were set to zero prior to first study drug dose and missing thereafter for the estimation of pharmacokinetic parameters.

A multivariate linear regression analysis of the log-transformed pharmacokinetic parameters was conducted to test for the independent relationships between pharmacokinetic parameters and pre-defined covariates: age (age category), gender, nutritional status (weight-for-age $\mathrm{z}$-score if $\leq 5$ years and an additional category for patients $>5$ years), $\mathrm{mg} / \mathrm{kg}$ total dose, presence or absence of fever at enrolment, parasite density ( $\geq 100,000$ versus $<100,000$ asexual parasites per microlitre), anaemia $(\mathrm{Hb}<8.0$ versus $\mathrm{Hb} \geq 8.0 \mathrm{~g} / \mathrm{dL}$ ) and site of sample collection (Navrongo versus Kintampo Health Research Centre). Cox-proportional hazard ratios with Breslow correction for ties were used to explore the effects of the days $2,3,7,14$ and 28 concentrations of amodiaquine and desethylamodiaquine on treatment response.

\section{Results}

Trial profile

Of the 666 potential study participants screened, 321 patients were enrolled for the therapeutic efficacy trial, with 308 (96\%) of these included in the pharmacokinetic study (Fig. 1). A total of 1900 samples were assayed for both amodiaquine and desethylamodiaquine concentrations. Of these, 64/308 (20.8\%) had quantifiable amodiaquine concentrations prior to dosing, so were retrospectively excluded from the pharmacokinetic analysis. In addition, 48 amodiaquine and 66 desethylamodiaquine data points considered biologically implausible were excluded, resulting in a total of 1432 amodiaquine and 1416 desethylamodiaquine concentrations from 233 patients being included in the pharmacokinetic analysis; 17 patients had insufficient quantifiable drug concentrations for calculating pharmacokinetic parameters (Fig. 1).

\section{Baseline characteristics}

Of the 308 patients enrolled into the pharmacokinetic study, $13(4.2 \%)$ were infants ( $<1$ year), $176(57.1 \%)$ children aged $1-4$ years and $119(38.6 \%)$ were aged 5 years or older (Table 1). Patients aged 5 years or older had lower baseline temperatures than younger patients $(\mathrm{p}=0.017)$. Overall, 47/308 (15.3\%) of the patients enrolled were moderate-to-severely anaemic $(\mathrm{Hb}<8 \mathrm{~g} / \mathrm{dL})$, most of whom $(37 / 47,79 \%)$ were $1-4$ years old. Of the children $\leq 5$ years old, $14.7 \%$ (28/190) were underweight-forage. The geometric mean parasite density at enrolment was $27,594(95 \%$ CI $23,737-32,079) / \mu \mathrm{L}$ overall and was lowest in infants $(15,879(95 \%$ CI $5,871-42,945) / \mu \mathrm{L}$ compared to $34,921(95 \%$ CI $28,916-42,172) / \mu \mathrm{L}$ in children aged $1-4$ years and $20,692(95 \% \mathrm{CI} 16,184-26,455) / \mu \mathrm{L}$ in older patients $(\mathrm{p}=0.001)$. The proportion of patients with parasite densities $\geq 100,000 / \mu \mathrm{L}$ was $15.3 \%$ (47/308), with most being children aged $1-4$ years $(32 / 47 ; 68.1 \%)$. Overall, the median total $\mathrm{mg} / \mathrm{kg}$ dose administered was 33.8 (IQR 27.0-40.5) $\mathrm{mg} / \mathrm{kg}$, with the $25.8 \mathrm{mg} / \mathrm{kg}$ administered to infants lower than the $33.8 \mathrm{mg} / \mathrm{kg}$ given to patients aged $1-4$ years $(p=0.004)$ or older $(p=0.010)$ (Table 1).

\section{Efficacy}

The crude (PCR-unadjusted) day 28 adequate clinical and parasitological response (ACPR) rate by intentionto-treat (ITT) analysis was $94.5 \%(291 / 308)$ [95\% CI 91.3, 96.8] and by per protocol (PP) analysis was $95.2 \%$ (280/294) [95\% CI 92.1, 97.4]. The overall day 28 PCRadjusted ACPR rate was 98.0\% (299/305) [95\% CI 95.8, 99.3] by ITT and $98.0 \%(288 / 294$ [95\% CI $95.6-99.2]$ by PP analysis. There was no difference in efficacy by ITT between patients aged $<5$ years $(97.9 \%)$ and those aged 


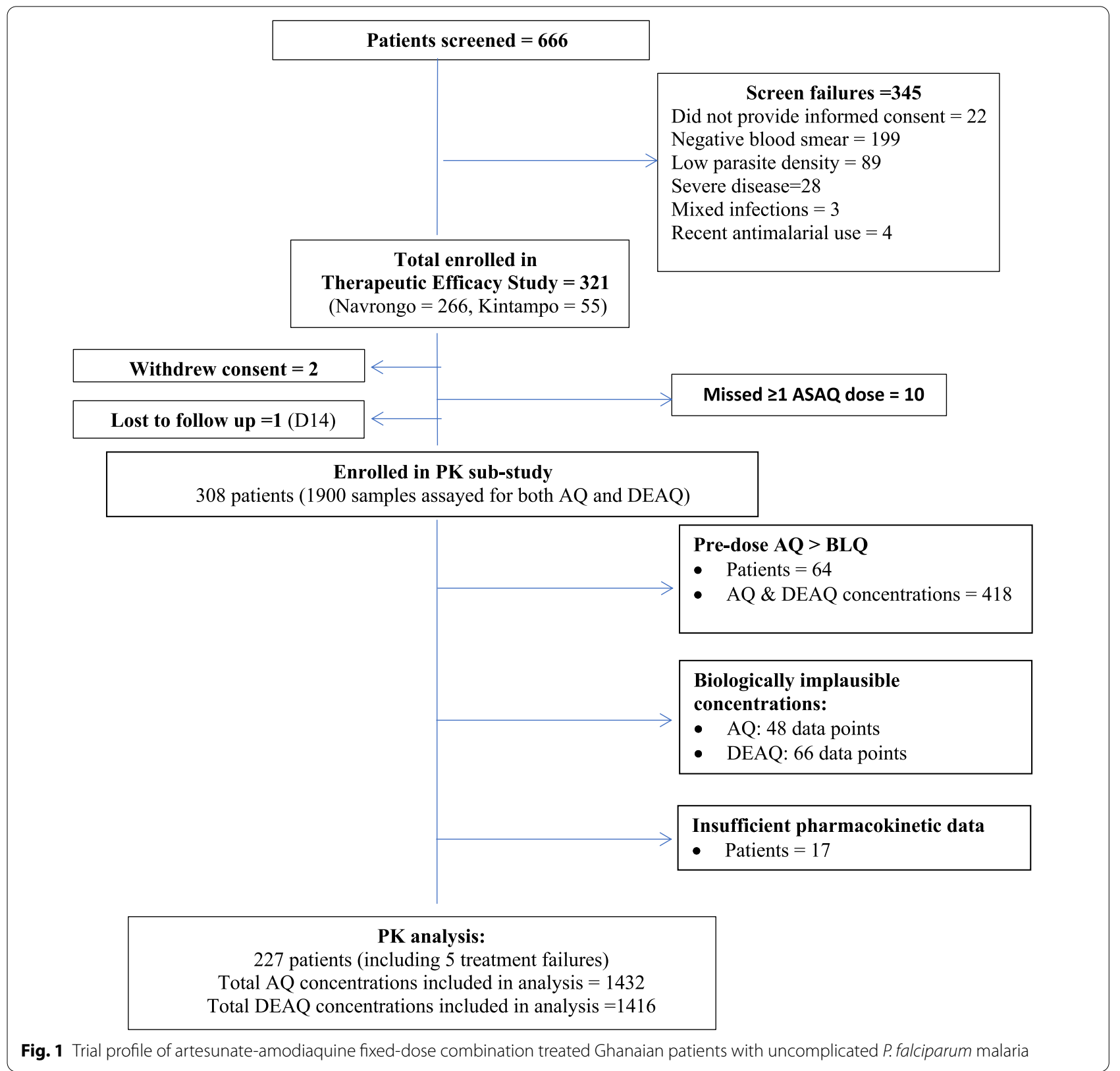

5 years or older $(98.3 \%), \mathrm{p}=0.8$ (Table 2). There were no early treatment failures. All recrudescences occurred on day 28 of follow up. Among patients who were re-dosed after vomiting post-dosing, 95.2\% (20/21) achieved an ACPR with only 1 recrudescent infection. Parasite clearance was rapid, with only one patient $(0.3 \%)$ still parasitaemic on day 3 post-treatment.

\section{Adverse events}

A total of 136 adverse events were documented in 66 (21.4\%) patients, many of which were consistent with features of malaria. All adverse events occurring within 28-days of follow up (Table 3) were mild or moderate and did not result in the discontinuation of treatment; there were no serious adverse events. The most common adverse events (occurring in $>1 \%$ of patients) were pyrexia $(8.1 \%)$, cough $(6.8 \%)$, asthenia $(5.2 \%)$, abdominal pain (4.2\%), upper respiratory tract infection (3.6\%), headache $(2.3 \%)$, diarrhoea $(2.3 \%)$, decreased appetite $(1.6 \%)$ and vomiting (1.3\%) (Table 3). The number of patients with Adverse Events was not higher among infants despite their higher amodiaquine exposure than older patients $(1 / 13,8.3 \%$ versus $25 / 284,8.1 \%$; $p=0.98)$. Nor were the number of adverse events higher in infants 
Table 1 Baseline characteristics of artesunate-amodiaquine fixed-dose combination treated Ghanaian patients with uncomplicated $P$. falciparum malaria

\begin{tabular}{|c|c|c|c|c|}
\hline & \multicolumn{4}{|l|}{ Age category (years) } \\
\hline & Total & $<1$ & $1-4$ & $\geq 5$ \\
\hline N (\%) & $308(100)$ & $13(4.2)$ & $176(57.1)$ & $119(38.6)$ \\
\hline Sex, Female, n (\%) & $161(52.3)$ & $8(61.5)$ & $92(52.3)$ & $61(51.3)$ \\
\hline Underweight ${ }^{\mathrm{b}}$ (WAZ<-2.00), n/N (\%) & $28 / 190(14.7)^{\mathrm{a}}$ & $0(0.0)$ & $26(13.6)$ & 2 \\
\hline Axillary temperature $\left({ }^{\circ} \mathrm{C}\right)$, mean $(\mathrm{SD})$ & $38.0(1.1)$ & $38.3(0.8)$ & $38.1(1.1)$ & $37.7(1.2)$ \\
\hline Haemoglobin (g/dL), mean (SD) & $10.0(1.9)$ & $8.5(1.3)$ & $9.5(1.8)$ & $11.0(1.8)$ \\
\hline $\begin{array}{l}\text { Moderate- to- severe anaemia patients } \\
(\mathrm{Hb}<8.0 \mathrm{~g} / \mathrm{dL}), \mathrm{n}(\%)\end{array}$ & $47(15.3)$ & $5(38.5)$ & $37(21.0)$ & $5(4.2)$ \\
\hline Severe anaemia $(\mathrm{Hb}<6.0 \mathrm{~g} / \mathrm{dL}), \mathrm{n}(\%)$ & $4(1.3)$ & $0(0)$ & $4(2.3)$ & $0(0)$ \\
\hline Geometric mean parasite density, $(95 \% \mathrm{Cl})$ & $27,594(23,737-32,079)$ & $15,879(5871-42,945)$ & $34,921(28,916-42,172)$ & $20,692(16,184-26,455)$ \\
\hline Parasite density $\geq 100,000, n(\%)$ & $47(15.3)$ & $3(23.1)$ & $32(18.2)$ & $12(10.1)$ \\
\hline Gametocyte Prevalence, n (\%) & $9(2.9)$ & $1(7.7)$ & $6(3.4)$ & $2(1.7)$ \\
\hline Total Dose (mg/ kg), median (IQR); range & $31.2(26.1-38.9) 7.6-52.6$ & $25.3(23.8-25.3) 13.4-31.15$ & $33.8(27.0-39.7) 14.5-45.0$ & $33.8(25.3-38.6) 7.2-52.6$ \\
\hline D0 AQ concentration > LLOQ, n (\%) & $64(20.8)$ & $0(0)$ & $45(25.6)$ & $19(16.0)$ \\
\hline
\end{tabular}

$\mathrm{N}=$ Sample population, $\mathrm{n}=$ number of patients in category, $\mathrm{WAZ}=$ weight-for-age $\mathrm{Z}$-score, $\mathrm{sd}=$ standard deviation, $\mathrm{Hb}=$ haemoglobin concentration, $\mathrm{Cl}=$ confidence interval, $\mathrm{mg} / \mathrm{kg}=$ milligram per kilogram, $\mathrm{IQR}=$ interquartile range, $\mathrm{D} 0=$ Day 0 pre-dose, $\mathrm{AQ}=$ amodiaquine, $\mathrm{BLQ}=$ below the limit of quantification

a Two patients aged 5 years

b WAZ score only calculated for children $\leq 5$ years; $2 / 13$ (15.4\%) children aged 5 years had WAZ score $<-2.00$

than older patients $(\mathrm{p}=0.93)$. The only infant who experienced adverse events developed gastroenteritis and an upper respiratory tract infection on day 42.

\section{Pharmacokinetic parameters of amodiaquine and desethylamodiaquine \\ Amodiaquine}

The capillary whole blood concentrations by day of follow up are shown in Fig. 2a and b, with the univariate analysis of pharmacokinetic parameters shown by age category in Table 4. The median area under the concentration-time curve to infinity $\left(\mathrm{AUC}_{0-\infty}\right)$ was 1318 (IQR 583-3,549) $\mathrm{ng} \mathrm{h} / \mathrm{mL}$ overall. Infants had a higher median (IQR) AUC $0-\infty$ of $4,201(2,773-17,909) \mathrm{ng} \mathrm{h} / \mathrm{mL}$, when compared to $1994(642-5,199) \mathrm{ng} \mathrm{h} / \mathrm{mL}$ in children aged $1-4$ years and $875(400-1434) \mathrm{ng} \mathrm{h} / \mathrm{mL}$ in those aged $\geq 5$ years $(\mathrm{p}<0.001)$. Overall, the median maximum amodiaquine concentration $\left(C_{\max }\right)$ was 18.8 (IQR 9.8-50.7) $\mathrm{ng} / \mathrm{mL}$, which was reached $\left(\mathrm{T}_{\max }\right)$ in a median of 2 (IQR 1-3) days. The median observed Cmax also decreased with age, from $49.6(21.7-107.0) \mathrm{ng} / \mathrm{mL}$ in infants, to 27.7 $(14.7-70.0) \mathrm{ng} / \mathrm{mL}$ in children aged $1-4$ years and 11.6 $(6.7-18.8) \mathrm{ng} / \mathrm{mL}$ in older children and adults $(\mathrm{p}<0.001)$. Median apparent clearance was 25.9 (IQR 8.6-56.0) L/ $\mathrm{kg} / \mathrm{h}$ overall, which increased with age, $\mathrm{p}<0.001$. The effects of age on amodiaquine $\mathrm{AUC}_{0-\infty}$ and on $\mathrm{C}_{\max }$ remained statistically significant when the two study sites were analysed separately, and the effect of age on apparent clearance was significant among the 198 patients enrolled in the Navrongo site, but not the smaller sample of 25 patients enrolled in the Kintampo site (Additional file 2). Median apparent volume of distribution was 1,195 (IQR 416-2735) L/kg, which also increased with age, $\mathrm{p}=0.008$. The terminal elimination half-life of amodiaquine was $47.4(32.4-72.8)$ hours and similar across age groups (Table 4).

After adjusting for pre-defined covariates (Table 5), there was a higher amodiaquine $\mathrm{AUC}_{0-\infty}$ [Geometric Mean Ratio (GMR) 5.42 (95\% CI 1.20-24.57), $\mathrm{p}=0.029$ ] and a trend towards a higher $\mathrm{C}_{\max }$ [GMR 2.69 (95\% CI 0.83-8.73), $\mathrm{p}=0.099$ ] in infants compared to those aged 5 years and older. There was a $4 \%$ increase in AUC $0-\infty$, [GMR 1.04 (95\% CI 1.01, 1.06), $\mathrm{p}=0.001$ ], and a $3 \%$ increase in $C_{\max }$ [GMR 1.03 (95\% CI 1.01, 1.05), $\mathrm{p}=0.001$ ] for each $1 \mathrm{mg} / \mathrm{kg}$ increase in total dose administered. Fever at enrolment was associated with a significant increase in $\mathrm{AUC}_{0-\infty}$ [GMR 1.44 (95\% CI 1.01-2.04), $\mathrm{p}=0.045]$, and $\mathrm{C}_{\max }$ [GMR 1.57 (95\% CI 1.18-2.09), $\mathrm{p}=0.002$ ] with a lower apparent clearance [GMR 0.69 (95\% CI 0.49-0.99), $\mathrm{p}=0.042$ ]. There was an $84 \%$ lower $\mathrm{AUC}_{0-\infty}$ [GMR 0.16 (95\% CI 0.09-0.27), $\mathrm{p}<0.001$ ] and an $82 \%$ lower $\mathrm{C}_{\max }$ [GMR 0.18 (95\% CI 0.12-0.28), $\mathrm{p}<0.001$ ] in patients from Navrongo compared to patients from Kintampo. This is consistent with the almost sevenfold increase in apparent clearance [GMR 6.82 (95\% CI $4.0-11.63), \mathrm{p}<0.001]$ and fourfold increase in the apparent volume of distribution [GMR 4.30 (95\% CI 2.208.39), $\mathrm{p}<0.001$ ] in patients from Navrongo compared to 
Table 2 Day 28 Therapeutic efficacy of artesunateamodiaquine fixed dose combination treatment of uncomplicated falciparum malaria in Ghanaian patients, by Intention-to-treat (ITT) and Per Protocol (PP) analysis

\begin{tabular}{|c|c|c|c|c|c|}
\hline \multirow[t]{2}{*}{ Treatment outcome } & \multirow[t]{2}{*}{ Analysis } & \multicolumn{4}{|c|}{ Age category (years) } \\
\hline & & Total & $<1$ & $1-4$ & $\geq 5$ \\
\hline \multirow[t]{2}{*}{ N } & ITT & 308 & 13 & 176 & 119 \\
\hline & PP & 294 & 11 & 168 & 115 \\
\hline \multirow{2}{*}{$\begin{array}{l}\text { Early treatment failure (ETF), } \\
\mathrm{n}(\%)\end{array}$} & ITT & 0 & 0 & 0 & 0 \\
\hline & PP & 0 & 0 & 0 & 0 \\
\hline \multirow[t]{2}{*}{ Late clinical failure (LCF), n (\%) } & ITT & $5(1.6)$ & 0 & $3(1.7)$ & $2(1.7)$ \\
\hline & PP & $5(1.7)$ & 0 & $3(1.8)$ & $2(1.7)$ \\
\hline \multirow{2}{*}{$\begin{array}{l}\text { Late parasitological failure } \\
(\text { (LPF), n (\%) }\end{array}$} & $\mathrm{ITT}$ & $12(3.9)$ & 0 & $6(3.5)$ & $6(5.0)$ \\
\hline & PP & $9(3.1)$ & 0 & $6(3.6)$ & $3(2.6)$ \\
\hline \multirow[t]{2}{*}{ D28 PCR-uncorrected ACPR, (\%) } & ITT & 94.5 & 100 & 94.9 & 93.3 \\
\hline & PP & 95.2 & 100 & 94.6 & 95.7 \\
\hline \multirow[t]{2}{*}{ Parasite recurrence, $\mathrm{n}$} & $\mathrm{ITT}$ & 17 & 0 & 9 & 8 \\
\hline & PP & 14 & 0 & 9 & 5 \\
\hline \multirow{2}{*}{$\begin{array}{l}\text { P. falciparum recrudescence on } \\
\text { PCR, } n\end{array}$} & $\mathrm{ITT}$ & 6 & 0 & 4 & 2 \\
\hline & PP & 6 & 0 & 4 & 2 \\
\hline \multirow{2}{*}{$\begin{array}{l}\text { P. falciparum reinfection on } \\
\text { PCR, } n\end{array}$} & $\mathrm{ITT}$ & 8 & 0 & 5 & 3 \\
\hline & PP & 8 & 0 & 5 & 3 \\
\hline \multirow{2}{*}{$\begin{array}{l}\text { alndeterminate or missing } \\
\text { PCR, } n\end{array}$} & ITT & 3 & 0 & 0 & 3 \\
\hline & PP & 0 & 0 & 0 & 0 \\
\hline \multirow{2}{*}{$\begin{array}{l}\text { Day } 28 \text { PCR-corrected ACPR, } \\
\text { (\%) }\end{array}$} & ITT & 98.0 & 100 & 97.7 & 98.3 \\
\hline & PP & 98.0 & 100 & 97.6 & 98.3 \\
\hline
\end{tabular}

PCR: Polymerase chain reaction; ACPR: Adequate clinical and parasitological response

a Patients with indeterminate or missing PCR results were excluded from PP and ITT analyses

Kintampo. Given that the elimination half-life was similar between the study sites, the differences observed by site could reflect differences in bioavailability.

\section{Desethylamodiaquine}

The capillary whole blood concentrations of desethylamodiaquine by day of follow up are displayed in Fig. 3a, $\mathrm{b}$ and univariate analysis of pharmacokinetic parameters by age category presented in Table 4 . Desethylamodiaquine concentrations were quantifiable in all patients throughout the 28-day follow up period. As expected, the peak concentrations and $\mathrm{AUC}_{0-\infty}$ of desethylamodiaquine were much larger than those for amodiaquine. The desethylamodiaquine terminal elimination half-life of $196.4 \mathrm{~h}$ was four-fold longer than that for amodiaquine. Maximum desethylamodiaquine concentrations increased with age $(\mathrm{p}=0.046)$, with a trend towards $\mathrm{AUC}_{0-\infty}(\mathrm{p}=0.057)$ decreasing with age and apparent clearance increasing with age $(\mathrm{p}=0.071)$. There was a strong linear correlation between the day 7
Table 3 Adverse events occurring within 28-days of artesunate-amodiaquine fixed dose combination treatment of uncomplicated falciparum malaria, by Intention-to-treat analysis

\begin{tabular}{lc}
\hline Adverse event & $\begin{array}{c}\text { Number of patients } \\
\text { reporting event } \mathbf{n} \text { (\%) }\end{array}$ \\
\hline Pyrexia & $25(8.1)$ \\
Cough & $21(6.8)$ \\
Asthenia & $16(5.2)$ \\
Abdominal pain & $13(4.2)$ \\
Upper respiratory tract infection & $11(3.6)$ \\
Headache & $7(2.3)$ \\
Diarrhoea & $7(2.3)$ \\
Decreased appetite & $5(1.6)$ \\
Vomiting & $4(1.3)$ \\
Gastroenteritis & $3(0.97)$ \\
Pruritis & $3(0.97)$ \\
Peripheral swelling & $3(0.97)$ \\
Pain & $2(0.65)$ \\
Oral pain & $2(0.65)$ \\
Restlessness & $2(0.65)$ \\
Otorrhoea & $2(0.65)$ \\
Dysentery & $2(0.65)$ \\
Furuncle & $2(0.65)$ \\
Abdominal distension & $1(0.32)$ \\
Dyspnea & $1(0.32)$ \\
Rash & $1(0.32)$ \\
Total & $136(44.2)$ \\
\hline
\end{tabular}

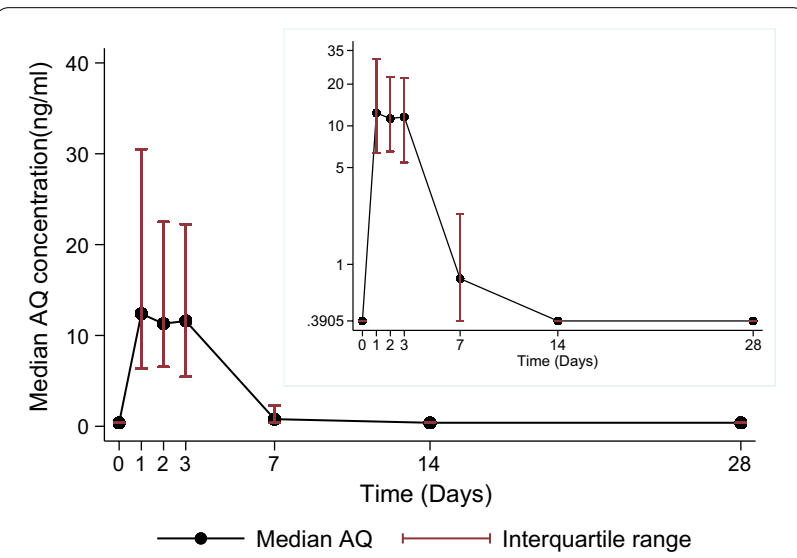

Fig. 2 A plot of the median (IQR) capillary whole blood amodiaquine (AQ) concentrations versus time overlaid with log-transformed $y$-axis plot of median (interquartile range) capillary whole blood amodiaquine concentrations $(\mathrm{ng} / \mathrm{ml}$ ) versus time in Ghanaian patients of all ages treated with 3-day course of artesunate-amodiaquine 
Table 4 Pharmacokinetic parameters of amodiaquine and desethylamodiaquine (median, IQR) following artesunateamodiaquine fixed-dose combination treatment of Ghanaian patients with uncomplicated $P$. falciparum malaria, by age category

\begin{tabular}{|c|c|c|c|c|c|}
\hline \multirow[t]{3}{*}{ Parameter } & \multicolumn{4}{|l|}{ Age category (years) } & \multirow[t]{3}{*}{ p-value } \\
\hline & All ages & $<1$ & $1-4$ & $\geq 5$ & \\
\hline & $n=223$ & $n=9$ & $n=125$ & $n=89$ & \\
\hline \multicolumn{6}{|l|}{ Amodiaquine } \\
\hline$A \cup C_{0-\infty}(\mathrm{ng} h / \mathrm{ml})$ & $1318(583-3549)$ & $4201(2773-17,909)$ & $1994(642-5199)$ & $875(400-1,434)$ & $<0.001$ \\
\hline$C_{\max }(\mathrm{ng} / \mathrm{ml})$ & $18.8(9.8-50.7)$ & $49.6(21.7-107.0)$ & $27.7(14.7-70.0)$ & $11.6(6.7-18.8)$ & $<0.001$ \\
\hline$T_{\max }$ (days) & $2(1-3)$ & $1(1-2)$ & $2(1-3)$ & $2(1-3)$ & 0.71 \\
\hline $\mathrm{Cl} / \mathrm{F}\left(\mathrm{L} \mathrm{kg}^{-1} \mathrm{~h}^{-1}\right)$ & $25.9(8.6-56.0)$ & $6.7(1.4-11.2)$ & $15.7(7.0-47.1)$ & $39.6(18.7-76.9)$ & $<0.001$ \\
\hline $\mathrm{Vd} / \mathrm{F}\left(\mathrm{L} \mathrm{kg}^{-1}\right)$ & $1,195(416-2,735)$ & $325(98-1141)$ & $859(359-2,613)$ & $1,840(861-3,656)$ & 0.008 \\
\hline \multirow[t]{2}{*}{$\mathrm{t}_{1 / 2}$ (hours) } & $47.4(32.4-72.8)$ & $54.1(24.6-148.7)$ & $48.8(32.6-87.9)$ & $41.7(32.4-56.1)$ & 0.24 \\
\hline & $n=227$ & $n=9$ & $n=127$ & $\mathrm{n}=91$ & \\
\hline \multicolumn{6}{|l|}{ Desethylamodiaquine } \\
\hline $\mathrm{AUC}_{0-\infty}(\mathrm{ng} \mathrm{h} / \mathrm{ml})$ & $116,100(70,325-203,110)$ & $163,020(94,262-255,562)$ & $124,508(79,736-225,582)$ & $105,596(56,986-159,382)$ & 0.057 \\
\hline$C_{\max }(\mathrm{ng} / \mathrm{ml})$ & $565(349-827)$ & $365(266-665)$ & $604(377-937)$ & $528(260-720)$ & 0.046 \\
\hline$T_{\max }$ (days) & $3(2-3)$ & $2(2-3)$ & $3(2-3)$ & $3(2-3)$ & 0.33 \\
\hline $\mathrm{Cl} / \mathrm{F}\left(\mathrm{L} \mathrm{kg}^{-1} \mathrm{~h}^{-1}\right)$ & $0.26(0.16-0.46)$ & $0.19(0.11-0.31)$ & $0.24(0.16-0.41)$ & $0.31(0.16-0.56)$ & 0.071 \\
\hline $\mathrm{Vd} / \mathrm{F}\left(\mathrm{L} \mathrm{kg}^{-1}\right)$ & $67.5(43.0-126.8)$ & $57.0(40.1-100.5)$ & $62.3(42.9-124.6)$ & $72.9(45.3-150.2)$ & 0.49 \\
\hline$t_{1 / 2}$ (hours) & $196.4(152.8-276.1)$ & $237.8(204.6-280.3)$ & $187.6(155.1-276.1)$ & 200.1 (137.5-268.6) & 0.60 \\
\hline
\end{tabular}

IQR Interquartile range, $\mathrm{AUC}_{0-\infty}$ Area under the concentration versus time curve from time zero to infinity, $\mathrm{ng} . \mathrm{h} / \mathrm{ml}$ nanogram hour per milliliter, $\mathrm{C}_{\max }=\mathrm{Observed}$ maximum concentration, $\mathrm{ng} / \mathrm{ml}$ nanogram per milliliter, $\mathrm{T}_{\max }$ time to maximum concentration, $\mathrm{CL} / \mathrm{f}$ apparent clearance, $\mathrm{Vd} / \mathrm{f}$ apparent volume of distribution, $t_{1 / 2}=$ elimination half-life

desethylamodiaquine concentrations and the $\mathrm{AUC}_{0-\infty}$; $\mathrm{r}_{\mathrm{s}}=0.881, \mathrm{p}<0.001$ (Fig. 4).

After adjusting for all other predefined covariates (Table 5), there was no association between desethylamodiaquine exposure and age or study site, in contrast with amodiaquine exposure. A $1 \mathrm{mg} / \mathrm{kg}$ increase in the total amodiaquine dose was associated with a $2 \%$ increase in the $\mathrm{AUC}_{0-\infty}$ [GMR 1.02 (95\% CI 1.00, 1.04), $\mathrm{p}=0.041$ ], which is substantial given the bodyweight adjusted total dose range between 23 and $45 \mathrm{mg} / \mathrm{kg}$. Although high baseline parasitaemia was associated with a $40 \%$ reduction in the elimination half-life compared with patients with parasite densities $<100,000 / \mu \mathrm{L}$ [GMR 1.40 (95\% CI $1.09,1.81), \mathrm{p}=0.008]$, no other pharmacokinetic parameters were affected by baseline parasite density (Table 5).

\section{Pharmacokinetic-pharmacodynamic relationship}

Treatment efficacy was very high in this study with a PCR-adjusted adequate clinical and parasitological response rate of over $97 \%$. The study was therefore underpowered to show any pharmacokinetic differences between patients who achieved an adequate clinical and parasitological response and those who failed treatment. Given the few treatment failures, treatment response categories were simplified to ACPR or treatment failure (i.e. any parasite recurrence). The median amodiaquine concentration on day 3 was significantly lower in patients with parasite recurrence than in those with an ACPR [ 4.8 (IQR 3.0-8.2) vs. 12.5 (IQR 5.9-24.2) $\mathrm{ng} / \mathrm{mL} ; \mathrm{p}=0.002$, Fig. 5]. A $1 \mathrm{ng} / \mathrm{mL}$ increase in median day 3 amodiaquine concentration was associated with a $13 \%$ reduction in the risk of parasite recurrence, $[\mathrm{HR}=0.8737$ (95\% CI $0.7793,0.9795), p=0.021]$. The day 7 desethylamodiaquine concentrations, $\mathrm{p}=0.767$, as well as total desethylamodiaquine exposure, $\mathrm{AUC}_{0-\infty}, \mathrm{p}=0.363$, were similar between patients who achieved ACPR and those with recurrent parasitaemia.

\section{Discussion}

Amodiaquine is rapidly and extensively metabolized to desethylamodiaquine, its main active metabolite that has a much longer elimination half-life than amodiaquine and generally provides most of its anti-malarial effect. This study demonstrates that desethylamodiaquine exposure in whole blood is remarkably consistent across all age groups, which is reassuring since the highest $P$. falciparum malaria burden is carried by children under 5 years of age [2]. This is in contrast to findings for a number of other widely used anti-malarials including lumefantrine, piperaquine, and sulfadoxine-pyrimethamine that appear to have been systematically underdosed in young children [37-39]. Equally reassuring is 
Table 5 Multivariate analysis of log-transformed Amodiaquine and Desethylamodiaquine pharmacokinetic parameters following artesunate-amodiaquine fixed-dose combination treatment of Ghanaian patients with uncomplicated $P$. falciparum malaria (geometric Mean Ratios (GMR) and 95\% Confidence Intervals (CI))

\begin{tabular}{|c|c|c|c|c|c|c|c|}
\hline \multirow[b]{2}{*}{$\begin{array}{l}\text { Area under the Curve } \\
\left(A \cup C_{0-\infty)}\right.\end{array}$} & GMR & $95 \% \mathrm{Cl}$ & \multicolumn{2}{|l|}{ p-value } & GMR & $95 \% \mathrm{Cl}$ & \multirow[t]{2}{*}{ p-value } \\
\hline & \multicolumn{4}{|c|}{ Amodiaquine $(n=196)$} & \multicolumn{2}{|c|}{ Desethylamodiaquine $(n=210)$} & \\
\hline $\begin{array}{l}\text { Age category: }<1 \text { ver- } \\
\text { sus } \geq 5 \text { years }\end{array}$ & 5.42 & 1.20 to 24.57 & \multicolumn{2}{|c|}{0.029} & 1.12 & 0.38 to 3.29 & 0.84 \\
\hline $\begin{array}{l}\text { Age category: } 1-4 \\
\text { versus } \geq 5 \text { years }\end{array}$ & 1.85 & 0.60 to 5.71 & \multicolumn{2}{|l|}{0.28} & 0.81 & 0.36 to 1.79 & 0.60 \\
\hline $\begin{array}{l}\text { Baseline Fever (Tempera- } \\
\text { ture: } \geq 37.5^{\circ} \mathrm{C} \text { ) }\end{array}$ & 1.44 & 1.01 to 2.04 & \multicolumn{2}{|l|}{0.045} & 1.13 & 0.87 to 1.47 & 0.37 \\
\hline $\begin{array}{l}\text { Underweight-for- } \\
\text { age: WAZ }<-2.0 \text { vs } \\
\text { WAZ } \geq-2.0\end{array}$ & 0.82 & 0.45 to 1.48 & \multicolumn{2}{|l|}{0.50} & 1.15 & 0.72 to 1.84 & 0.55 \\
\hline $\begin{array}{l}\text { Underweight-for-age: } \\
\text { NA vs WAZ } \geq-2.0\end{array}$ & 0.82 & 0.26 to 2.57 & \multicolumn{2}{|l|}{0.74} & 0.68 & 0.31 to 1.53 & 0.35 \\
\hline Dose $(\mathrm{mg} / \mathrm{kg})$ & 1.04 & 1.01 to 1.06 & \multicolumn{2}{|l|}{0.001} & 1.02 & 1.00 to 1.04 & 0.041 \\
\hline Sex: Female (vs. male) & 0.74 & 0.54 to 1.01 & \multicolumn{2}{|l|}{0.058} & 0.87 & 0.68 to 1.12 & 0.28 \\
\hline $\begin{array}{l}\text { Parasite den- } \\
\text { sity }<100,000 \\
(v s \geq 100,000 / \mu \mathrm{L})\end{array}$ & 0.91 & 0.58 to 1.42 & \multicolumn{2}{|l|}{0.67} & 1.13 & 0.81 to 1.58 & 0.46 \\
\hline Anaemia: $\mathrm{Hb}<8.0 \mathrm{~g} / \mathrm{dL}$ & 1.44 & 0.87 to 2.36 & \multicolumn{2}{|l|}{0.15} & 1.20 & 0.81 to 1.78 & 0.35 \\
\hline $\begin{array}{l}\text { Site: Navrongo (vs } \\
\text { Kintampo) }\end{array}$ & 0.16 & 0.09 to 0.27 & \multicolumn{2}{|l|}{$<0.001$} & 1.12 & 0.73 to 1.71 & 0.61 \\
\hline \multicolumn{5}{|l|}{$\begin{array}{l}\text { Prior AQ use: Day } 0 \\
\text { DEAQ }>20 \mathrm{ng} / \mathrm{mL}\end{array}$} & 1.23 & 0.93 to 1.63 & 0.14 \\
\hline \multicolumn{2}{|c|}{ Maximum concentration (Cmax) } & Amo & uine $(n=217)$ & & Deset & e $(n=211)$ & \\
\hline Age category: $<1$ versus $>$ & 5 years & 2.69 & 0.83 to 8.73 & 0.099 & 0.73 & 0.26 to 2.00 & 0.54 \\
\hline Age category: $1-4$ versus & $\geq 5$ years & 2.30 & 0.93 to 5.65 & 0.071 & 0.86 & 0.40 to 1.85 & 0.69 \\
\hline Baseline Fever (Temperatu & ure: $\left.\geq 37.5^{\circ} \mathrm{C}\right)$ & 1.57 & 1.18 to 2.09 & 0.002 & 1.17 & 0.91 to 1.51 & 0.22 \\
\hline Underweight-for-age: WA & $Z<-2.0$ vs $W A Z \geq-2.0$ & 0.63 & 0.38 to 1.05 & 0.075 & 1.08 & 0.69 to 1.70 & 0.72 \\
\hline Underweight-for-age: NA & vs $W A Z \geq-2.0$ & 0.95 & 0.38 to 2.36 & 0.90 & 0.69 & 0.32 to 1.51 & 0.36 \\
\hline Dose (mg/kg) & & 1.03 & 1.01 to 1.05 & 0.001 & 1.01 & 1.00 to 1.03 & 0.14 \\
\hline Sex: Female (vs. male) & & 0.80 & 0.62 to 1.05 & 0.105 & 0.85 & 0.67 to 1.07 & 0.17 \\
\hline Parasite density $<100,000$ & (vs $\geq 100,000 / \mu L)$ & 0.77 & 0.53 to 1.13 & 0.18 & 1.09 & 0.79 to 1.50 & 0.62 \\
\hline Anaemia: $\mathrm{Hb}<8.0 \mathrm{~g} / \mathrm{dL}$ & & 1.72 & 1.12 to 2.64 & 0.013 & 1.23 & 0.85 to 1.79 & 0.27 \\
\hline Site: Navrongo (vs Kintamp & & 0.18 & 0.12 to 0.28 & $<0.001$ & 1.36 & 0.90 to 2.05 & 0.14 \\
\hline Prior AQ use: Day 0 DEAQ & $>20$ ng/mL & & & & 1.18 & 0.90 to 1.54 & 0.23 \\
\hline Apparent Clearance $(\mathrm{Cl} / 1$ & & Amo & dine $(n=196)$ & & Deset & e $(n=210)$ & \\
\hline Age category: $<1$ versus $>$ & 5 years & 0.20 & 0.04 to 0.89 & 0.035 & 0.95 & 0.32 to 2.81 & 0.92 \\
\hline Age category: $1-4$ versus & $\geq 5$ years & 0.55 & 0.18 to 1.71 & 0.30 & 1.27 & 0.57 to 2.84 & 0.56 \\
\hline Baseline Fever (Temperatu & re: $\left.\geq 37.5^{\circ} \mathrm{C}\right)$ & 0.69 & 0.49 to 0.99 & 0.042 & 0.88 & 0.67 to 1.15 & 0.34 \\
\hline Underweight-for-age: WA & $Z<-2.0$ vs $W A Z \geq-2.0$ & 1.23 & 0.67 to 2.23 & 0.50 & 0.87 & 0.54 to 1.39 & 0.56 \\
\hline Underweight-for-age: NA & vs $W A Z \geq-2.0$ & 1.22 & 0.39 to 3.84 & 0.73 & 1.47 & 0.65 to 3.33 & 0.35 \\
\hline Dose $(\mathrm{mg} / \mathrm{kg})$ & & 1.00 & 0.98 to 1.02 & 0.79 & 1.01 & 1.00 to 1.03 & 0.093 \\
\hline Sex: Female (vs. male) & & 1.34 & 0.98 to 1.85 & 0.070 & 1.13 & 0.88 to 1.45 & 0.34 \\
\hline Parasite density $<100,000$ & (vs $\geq 100,000 / \mu \mathrm{L})$ & 1.10 & 0.7 to 1.71 & 0.69 & 0.88 & 0.63 to 1.24 & 0.46 \\
\hline Anaemia: $\mathrm{Hb}<8.0 \mathrm{~g} / \mathrm{dL}$ & & 0.70 & 0.42 to 1.16 & 0.16 & 0.83 & 0.56 to 1.24 & 0.37 \\
\hline Site: Navrongo (vs Kintamp & ро) & 6.82 & 4.00 to 11.63 & $<0.001$ & 0.97 & 0.63 to 1.50 & 0.91 \\
\hline Prior AQ use: Day O DEAQ & $>20$ ng/mL & & & & 0.81 & 0.61 to 1.07 & 0.13 \\
\hline
\end{tabular}

Apparent Volume of distribution (Vd/f) Amodiaquine $(n=152)$

Desethylamodiaquine $(n=209)$

\begin{tabular}{lllllll}
\hline Age category: $<1$ versus $\geq 5$ years & 0.62 & 0.07 to 5.39 & 0.66 & 0.74 & 0.19 to 2.82 & 0.65
\end{tabular}


Table 5 (continued)

\begin{tabular}{|c|c|c|c|c|c|c|}
\hline \multirow{2}{*}{$\begin{array}{l}\text { Apparent Volume of distribution }(\mathbf{V d} / \mathbf{f}) \\
\text { Age category: } 1-4 \text { versus } \geq 5 \text { years }\end{array}$} & \multicolumn{3}{|c|}{ Amodiaquine $(n=152)$} & \multicolumn{3}{|c|}{ Desethylamodiaquine $(n=209)$} \\
\hline & 0.67 & 0.11 to 4.21 & 0.67 & 0.84 & 0.32 to 2.19 & 0.72 \\
\hline Baseline Fever (Temperature: $\geq 37.5^{\circ} \mathrm{C}$ ) & 0.67 & 0.42 to 1.09 & 0.10 & 0.71 & 0.50 to 1.00 & 0.050 \\
\hline $\begin{array}{l}\text { Underweight-for-age: } W A Z<-2.0 \text { vs } \\
\text { WAZ } \geq-2.0\end{array}$ & 1.44 & 0.7 to 2.99 & 0.32 & 0.91 & 0.50 to 1.65 & 0.76 \\
\hline Underweight-for-age: NA vs WAZ $\geq-2.0$ & 1.16 & 0.18 to 7.26 & 0.88 & 0.95 & 0.36 to 2.51 & 0.91 \\
\hline Dose $(\mathrm{mg} / \mathrm{kg})$ & 1.01 & 0.98 to 1.04 & 0.42 & 1.02 & 1.00 to 1.05 & 0.044 \\
\hline Sex: Female (vs. male) & 0.93 & 0.61 to 1.42 & 0.74 & 1.23 & 0.90 to 1.7 & 0.20 \\
\hline Parasite density $<100,000(\mathrm{vs} \geq 100,000 / \mu \mathrm{L})$ & 0.78 & 0.43 to 1.4 & 0.41 & 1.19 & 0.76 to 1.85 & 0.45 \\
\hline Anaemia: $\mathrm{Hb}<8.0 \mathrm{~g} / \mathrm{dL}$ & 0.54 & 0.28 to 1.05 & 0.070 & 0.75 & 0.45 to 1.25 & 0.27 \\
\hline Site: Navrongo (vs Kintampo) & 4.30 & 2.20 to 8.39 & $<0.001$ & 0.76 & 0.44 to 1.31 & 0.32 \\
\hline \multicolumn{4}{|l|}{ Prior AQ use: Day 0 DEAQ > 20 ng/mL } & 0.86 & 0.59 to 1.24 & 0.41 \\
\hline Elimination half-life $\left(t^{1} / 2\right)$ & \multicolumn{3}{|c|}{ Amodiaquine $(n=152)$} & \multicolumn{3}{|c|}{ Desethylamodiaquine $(n=208)$} \\
\hline Age category: $<1$ versus $\geq 5$ years & 1.82 & 0.59 to 5.6 & 0.29 & 1.05 & 0.49 to 2.21 & 0.91 \\
\hline Age category: $1-4$ versus $\geq 5$ years & 1.78 & 0.75 to 4.18 & 0.19 & 0.90 & 0.52 to 1.53 & 0.69 \\
\hline Baseline Fever (Temperature: $\geq 37.5^{\circ} \mathrm{C}$ ) & 0.95 & 0.72 to 1.24 & 0.70 & 0.85 & 0.70 to 1.03 & 0.103 \\
\hline $\begin{array}{l}\text { Underweight-for-age: WAZ }<-2.0 \text { vs } \\
\text { WAZ } \geq-2.0\end{array}$ & 0.98 & 0.65 to 1.48 & 0.92 & 0.95 & 0.68 to 1.32 & 0.74 \\
\hline Underweight-for-age: NA vs WAZ $\geq-2.0$ & 1.39 & 0.59 to 3.29 & 0.45 & 0.84 & 0.49 to 1.45 & 0.52 \\
\hline Dose $(\mathrm{mg} / \mathrm{kg})$ & 1.01 & 0.99 to 1.02 & 0.54 & 1.01 & 1.00 to 1.02 & 0.18 \\
\hline Sex: Female (vs. male) & 0.74 & 0.58 to 0.94 & 0.013 & 1.08 & 0.90 to 1.29 & 0.41 \\
\hline Parasite density < 100,000 (vs $\geq 100,000 / \mu \mathrm{L})$ & 0.84 & 0.61 to 1.17 & 0.31 & 1.41 & 1.09 to 1.81 & 0.008 \\
\hline Anaemia: $\mathrm{Hb}<8.0 \mathrm{~g} / \mathrm{dL}$ & 0.94 & 0.64 to 1.36 & 0.73 & 0.91 & 0.69 to 1.21 & 0.52 \\
\hline Site: Navrongo (vs Kintampo) & 0.85 & 0.58 to 1.24 & 0.39 & 0.86 & 0.63 to 1.16 & 0.31 \\
\hline Prior AQ use: Day 0 DEAQ > 20 ng/mL & & & & 1.08 & 0.88 to 1.32 & 0.48 \\
\hline
\end{tabular}

WAZ Weight for Age z-score, NA Not applicable (WAZ score only calculated for children $\leq 5$ years), AQ amodiaquine, DEAQ desethylamodiaquine,

that desethylamodiaquine exposure is not reduced in underweight-for-age young children or those with a high parasitaemia, two of the most vulnerable target population groups.

The inclusion of infants with uncomplicated malaria in this study provides preliminary evidence that they may have greater exposure to amodiaquine than older children and adults. There was a significant decrease in total amodiaquine exposure and maximum concentration with age, even when study sites were analysed separately (Table 4 and Additional file 2). After adjusting for covariates, there was a higher amodiaquine total exposure, with a trend towards a higher maximum concentration and a slower apparent clearance in the 9 infants included in the pharmacokinetic analysis (Table 5). No safety concerns were identified in this study, despite the higher amodiaquine concentrations observed in infants relative to older children and adults. Consistent with the safety findings, the maximum amodiaquine concentrations observed in infants in this study were similar to whole blood concentrations reported after a single oral dose of $600 \mathrm{mg}$ amodiaquine in 7 healthy adult males [29] and in plasma concentrations in Zambian and Nigerian malaria patients aged $7-55$ years [17], and much lower than the plasma concentrations reported in Ugandan patients aged 1.5-8 years [40]. A larger prospective pharmacokinetic study including infants and young children with close monitoring of safety, including full blood counts and liver function tests, is needed to confirm the higher amodiaquine exposure in infants and understand any safety implications.

Age-dependent changes in body composition or maturational effects may contribute to the pharmacokinetic differences by age group [41], and amodiaquine and desethylamodiaquine clearance increase with age and bodyweight $[42,43]$. Amodiaquine is primarily metabolised by Cytochrome P450 isoenzyme 2C8 (CYP2C8), and its expression increases with age [42-45]. However, classification tree analysis of CYP2C8 expression indicates two nodes for age stratification, namely 35 days and 11 years, with no indication of a difference in CYP2C8 expression between older infants (including all infants in this study whose ages range between 5.2 and 11.5 months) and children under 12 years of age [44].

Although there was a trend towards total desethylamodiaquine exposure and apparent clearance decreasing with age, its pharmacokinetic parameters did not 


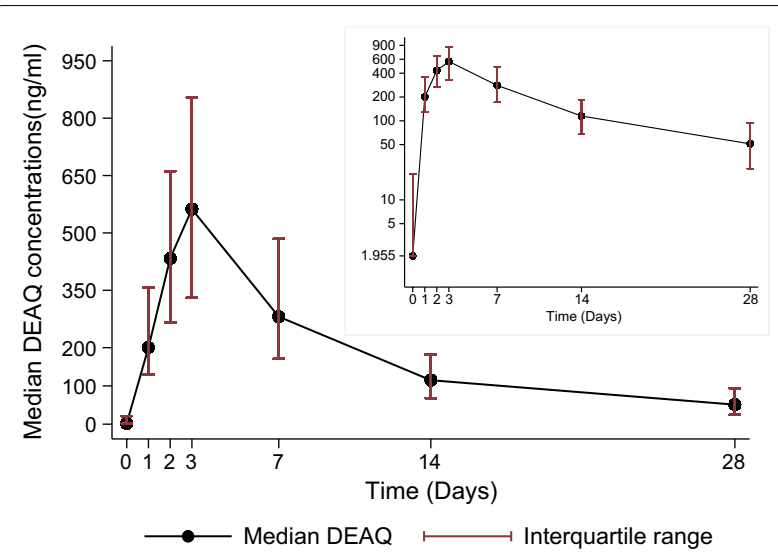

Fig. 3 A plot of the median capillary whole blood desethylamodiaquine (DEAQ) concentrations versus time profile overlaid with log-transformed $y$-axis plot of the median (interquartile range) capillary whole blood desethylamodiaquine concentrations versus time in Ghanaian patients of all ages treated with 3-day course of artesunate-amodiaquine

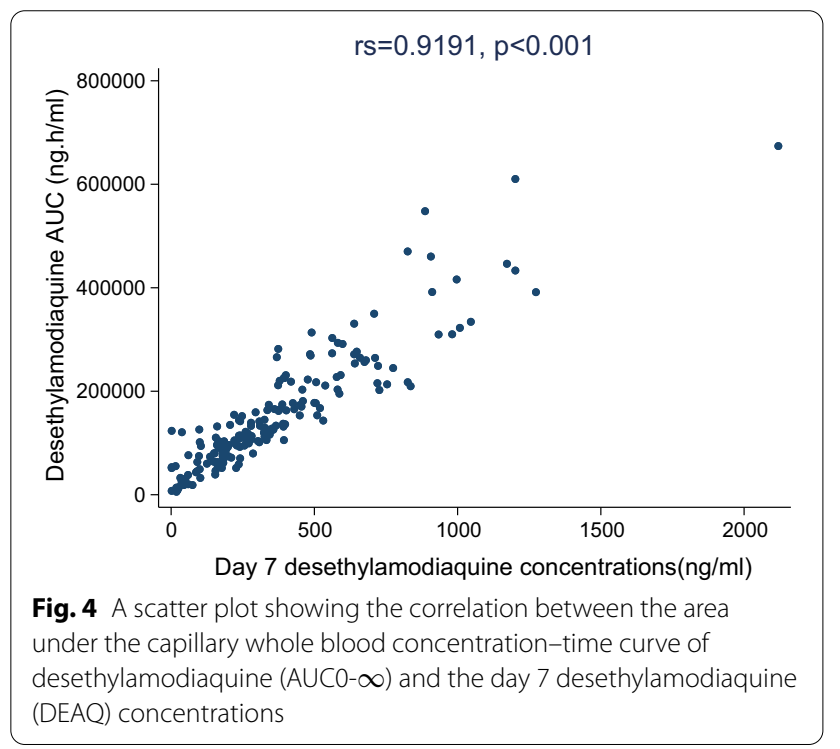

differ significantly between age categories after adjusting for pre-defined covariates. The median capillary whole blood desethylamodiaquine $\mathrm{AUC}_{0-\infty}$ in this study is similar to those obtained in whole blood spots from malaria patients aged 1-10 years in Papua New Guinea [18], but about 3-times higher than that previously reported in plasma samples in Ghanaian malaria patients aged 1-14 years [20]. Similarly, the whole blood amodiaquine $\mathrm{AUC}_{0-\infty}$ in this study was substantially higher than the few published amodiaquine $\mathrm{AUC}_{0-\infty}$ values reported, all of which were measured in plasma $[22,29,46]$. These differences may reflect

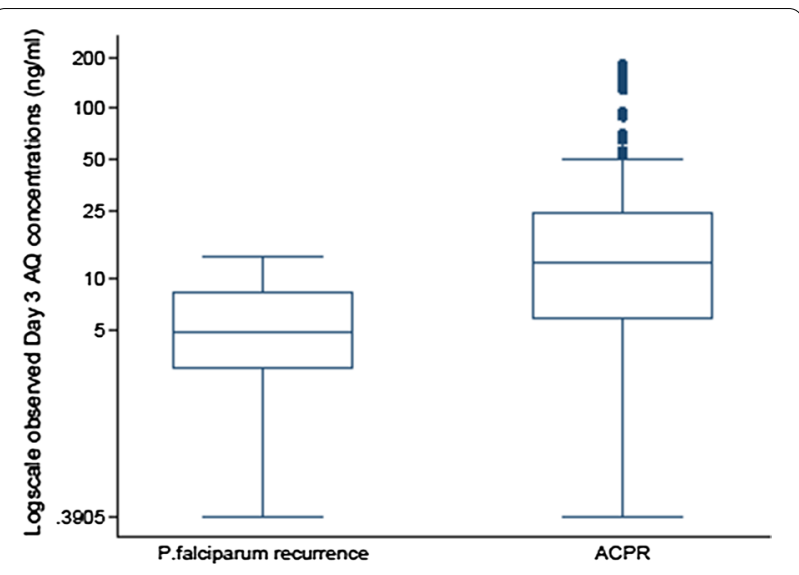

Fig. 5 Box and whisker plots of log scale observed Day 3 amodiaquine concentrations by treatment response

matrix effects, with amodiaquine and desethylamodiaquine being concentrated in the white blood cells [2426], and greater sensitivity of the assay developed in this study. Genotyping was not included in this study, so the contribution of slow metabolisers (CYP2C8*2) of amodiaquine could not be excluded, although previous studies suggest a prevalence between 16 and $18 \%$ in Ghana [20, 47, 48].

No safety concerns were identified in this study, with all adverse events mild to moderate and many consistent with malaria features. Although safety was assessed clinically at all scheduled and unscheduled study visits, it was not feasible to perform laboratory tests to monitor for neutropenia or hepatotoxicity, which have been associated with amodiaquine use particularly when taken as chemoprophylaxis or with interacting medicines [3, 49, 50]. The proportion of patients reporting adverse events in this study was lower than previously reported in children in the two study areas $[8,9]$. One explanation may be that the co-blistered artesunate-amodiaquine tablets (used in the two other studies) have been associated with less accurate dosing, and higher doses may lead to more side effects [51,52]. These differences may also reflect methods used in eliciting adverse events, with the inclusion of additional laboratory investigations (such as differential white blood cell counts and liver function tests) and different methods of questioning that have been shown to influence safety data [53].

In 2005, Ghana replaced chloroquine with the artemisinin-based combination treatment, artesunateamodiaquine, given as loose tablets or co-blister packs for the treatment of uncomplicated malaria [4]. This study provides reassurance that the efficacy of the fixed dose combination of artesunate-amodiaquine remained high 7 to 8 years after its deployment in Ghana, with 
genotype-corrected ACPR rates by day 28 above $97 \%$ confirmed across all age categories and by both intention-to-treat and per protocol analysis, with only one patient $(0.3 \%)$ still parasitaemic on microscopy on day 3. This may in part reflect the improved efficacy of the fixed dose combination. In a large pooled individual patient data meta-analysis of 9106 patients treated with artesunate-amodiaquine, the day 28 genotype-corrected ACPR rate of the fixed-dose combination was superior to loose tablet combinations [52]. However, there is the need for therapeutic efficacy studies to be repeated regularly and with optimal follow up [30,54], in order to assess whether the efficacy of artesunate-amodiaquine has been sustained, particularly in the light of sporadic reports of indigenous artemisinin-resistant $P$. falciparum in Africa [55-57].

All patients in this study had quantifiable concentrations of desethylamodiaquine on day 28 , showing that longer follow up would be needed to detect all treatment failures, as recrudescent parasitaemia may be suppressed by these quantifiable drug concentrations $[24,30$, 54]. Earlier reports suggest that the formation of desethylamodiaquine from amodiaquine is rapid with very little of the parent drug, amodiaquine, being detectable in plasma beyond the third day post-dose [18, 29, 58]. However, similar to Ntale et al. [41], amodiaquine concentrations in this study were still quantifiable later in a substantial proportion $(35.8 \%)$ of patients on day 7 and in $13 \%$ of patients on day 28 , possibly reflecting the greater amodiaquine exposure in the infants and young children included, the greater sensitivity of the assay used and possibly also the relatively high prevalence of CYP2C $8 * 2$ in Ghana [20, 47, 48, 59].

Assessments of amodiaquine/desethylamodiaquine concentrations should be included in these therapeutic efficacy studies wherever possible, at least on day 7 and before starting treatment [60]. In holo-endemic areas like Ghana, repeated use of anti-malarials is common and often undisclosed [61]. This is reflected by over $20 \%$ of enrolled patients in this study having quantifiable amodiaquine concentrations prior to dosing despite excluding patients who reported recent anti-malarial treatment.

In sub-Saharan Africa, malaria and malnutrition often co-exist and are important public health conditions. It is estimated that 1 in 3 children under 5 years of age in sub-Saharan Africa suffer from malnutrition [62]. Malnutrition has been observed to alter the pharmacokinetic properties of chloroquine and quinine [3]. A pooled individual patient data analysis showed that Day 7 lumefantrine concentrations were lower and reinfection rates higher in underweight young children than adequately nourished children and adults; similar findings were seen in children with severe acute malnutrition when compared with well-nourished children $[63,64]$. In this study however, the 28 (14.7\%) underweight-for-age children aged $\leq 5$ years did not have significant changes in amodiaquine or desethylamodiaquine pharmacokinetic parameters. Similarly, amodiaquine and desethylamodiaquine exposure was not altered in the 47 patients with a high parasitaemia at enrolment, despite their shorter elimination half-life. This provides reassuring evidence of the accuracy of the currently recommended dosing in these important vulnerable populations.

Study site appeared to be an important factor affecting the pharmacokinetic parameters of amodiaquine, despite adjustments for other predefined covariates. However, the pharmacokinetic properties of the active metabolite responsible for most anti-malarial activity, desethylamodiaquine were similar between sites. While the exact reason for the disparities observed by site of sample collection is not known, these differences may be consistent with higher amodiaquine bioavailability in Kintampo than Navrongo. Although it is possible that more patients Kintampo had non-protocol high-fat intake before dosing, this alone would not fully explain the apparent site effects. Compared with the fasted state in healthy adult volunteers, a high fat meal given before dosing had relatively modest effects, delaying absorption slightly and increasing both Cmax (by 22\% for amodiaquine and $21 \%$ for desethylamodiaquine) and AUC (by $59 \%$ for amodiaquine and $13 \%$ for desethylamodiaquine) [65]. It has been suggested that ethnicity and concomitant medication use [59, 66-68] are among other factors that may account for unexplained site effects. Concomitant medication use reported in both study sites was similar, with paracetamol and iron/multivitamin supplements most commonly reported in both sites. Ethnically, however, the two study sites are distinct. The main indigenous groups in Kintampo are the Bono and the Mo, while the Kassena and the Nankana are the main two distinct ethnolinguistic groups in the Navrongo area. Ethnic differences could be explained by potential differences in prevalence of CYP2C $8 * 2$ but no data is available on the pharmacogenetic profiles of these ethnic groups.

A simple liquid-liquid extraction method coupled with LC-MS/MS detection that uses a small volume of whole blood $(20 \mu \mathrm{L})$ was developed and fully validated in this study for the simultaneous determination of amodiaquine and its active metabolite, desethylamodiaquine. The method achieved lower limits of detection relative to the small sample volume, with good sensitivity and reproducibility. Small sample volumes may be necessary for field studies to ease sample collection, particularly from infants and small children. This method can readily be used for pharmacokinetic studies and therapeutic drug monitoring in patients and at-risk groups, including 
children to whom amodiaquine based combinations are given for the treatment or prevention of falciparum malaria.

\section{Conclusion}

This large study of the pharmacokinetic properties of amodiaquine when used with artesunate for the treatment of uncomplicated malaria provides reassuring evidence of high cure rates with desethylamodiaquine exposure remarkably consistent across all age groups, including in underweight-for-age children and those with hyperparasitaemia. The inclusion of infants with uncomplicated malaria in this study provides preliminary evidence that they may have greater exposure to amodiaquine than older children and adults. Although no safety concerns were identified in this study, there is the potential for more adverse events in infants given their higher amodiaquine exposure and observed maximum concentrations (Cmax), particularly with increasing deployment of seasonal malaria chemoprophylaxis (SMC) in the Sahel region where 81 million courses of SP-amodiaquine were delivered in 2018 [69]. In addition to the need for heightened pharmacovigilance in infants treated with amodiaquine, a larger pharmacokinetic study with close monitoring of safety, including full blood counts and liver function tests, is needed to confirm the higher amodiaquine exposure in infants, understand any safety implications and assess whether dose optimization in this vulnerable, understudied population is needed.

\section{Supplementary Information}

The online version contains supplementary material available at https://doi. org/10.1186/s12936-020-03553-6.

Additional file 1. Liquid chromatography tandem mass spectrometry assay methods.

Additional file 2. Pharmacokinetic parameters (median, IQR) of amodiaquine and desethylamodiaquine following artesunate-amodiaquine fixed-dose combination treatment of Ghanaian patients with uncomplicated P. falciparum malaria, by study site and age category.

\section{Acknowledgements}

The authors wish to thank all study participants, staff of the Navrongo and Kintampo Health Research Centres, Division of Clinical Pharmacology, UCT for their participation and support during the conduct of the study. We are also grateful to the INESS secretariat for allowing us to conduct our study as a substudy on the main efficacy trial.

\section{Authors' contributions}

Conceptualization: KB, LW, ATA, Data collection: ATA, AF, DD, OB, Data curation: ATA, PD, EA, LW, KM, Pharmacokinetic assay: LW, ATA, SC, Statistical analysis: ATA, PD, KB, KM, Writing, review \& editing: ATA, SC, KM, AF, BO, AO, DD, KPA, $\mathrm{SOA}, \mathrm{AD}, \mathrm{AH}, \mathrm{FB}, \mathrm{LW}, \mathrm{EA}, \mathrm{PD}, \mathrm{LW}, \mathrm{KIB}$. All authors read and approved the final manuscript.

\section{Funding}

The funding for the parent study was from the Bill and Melinda Gates Foundation through the INDEPTH Network. Funding for the pharmacokinetic work was from the National Research Fund awarded to Prof Karen I. Barnes. Financial support towards the PhD studies was received from the University of Cape Town International student scholarship, the Faculty Health Sciences student scholarship and the Navrongo Health Research Centre.

\section{Availability of data and materials}

The datasets generated and/or analysed during the current study are available in the WorldWide Antimalarial Resistance Network (WWARN) repository [http://www.wwarn.org/].

\section{Ethics approval and consent to participate}

The parent study was approved by the Ghana Health Service Ethical Review committee, the Navrongo Health Research Centre Institutional Review board (NHRCIRB) and Kintampo Health Research Centre Ethical Review Committee. The pharmacokinetic sub-study was approved by the University of Cape Town Faculty of Health Sciences Human Research Ethics Committee and the NHRCIRB. The study was conducted according to the ethical principles of the Declaration of Helsinki [70], Good Clinical Practice [71] and local ethical and regulatory requirements. Written informed consent was obtained from all patients aged 18 years or older prior to the performance of study related procedures, such as collection of blood samples for drug concentration measurements, filter paper for genotyping and urine samples for pregnancy tests. Informed consent was obtained from the parents or guardians of patients aged less than 18 years. In addition, assent was obtained from patients $12-17$ years.

\section{Consent for publication}

Not applicable.

\section{Competing interests}

The authors declare that they have no competing interests.

\section{Author details}

1 Division of Clinical Pharmacology, Department of Medicine, University of Cape Town, Cape Town, South Africa. ${ }^{2}$ UCT/MRC Collaborating Centre for Optimising Antimalarial Therapy (CCOAT), University of Cape Town, Cape Town, South Africa. ${ }^{3}$ Navrongo Health Research Centre, Navrongo, Ghana. ${ }^{4}$ Department of Statistical Sciences, University of Cape Town, Cape Town, South Africa. ${ }^{5}$ Dodowa Health Research Centre, Dodowa, Ghana. ${ }^{6}$ Centre for Clinical Research, Kenya Medical Research Institute, Nairobi, Kenya. ${ }^{7}$ Kintampo Health Research Centre, Kintampo, Ghana. ${ }^{8}$ University for Health and Allied Sciences, Ho, Volta Region, Ghana. ${ }^{9}$ Ghana Standards Authority, Accra, Ghana. ${ }^{10}$ Research and Development Division, Ghana Health Service, Accra, Ghana.

Received: 3 July 2020 Accepted: 15 December 2020

Published online: 06 January 2021

\section{References}

1. Alonso PL, Tanner M. Public health challenges and prospects for malaria control and elimination. Nat Med. 2013;19:150-5.

2. WHO. World malaria report 2019. Geneva: World Health Organization; 2019. https://www.who.int/publications/i/item/9789241565721. Accessed 5 Nov 2020.

3. WHO. Guidelines for the treatment of malaria. 3rd Edn. Geneva: World Health Organization; 2015. https://www.who.int/docs/default-source/ documents/publications/gmp/guidelines-for-the-treatment-of-malar ia-eng.pdf?sfvrsn=a0138b77_2. Accessed 5 Nov 2020.

4. Ghana Ministry of Health. Anti-Malaria Drug Policy for Ghana. Ministry of Health; 2009. https://www.ghanahealthservice.org/downloads/GHS_ Antimalaria_drug_policy.pdf. Accessed 5 Nov 2020.

5. Koram KA, Abuaku B, Duah N, Quashie N. Comparative efficacy of antimalarial drugs including ACTs in the treatment of uncomplicated malaria among children under 5 years in Ghana. Acta Trop. 2005;95:194-203.

6. Koram K, Quaye L, Abuaku B. Efficacy of amodiaquine/artesunate combination therapy for uncomplicated malaria in children under five years in Ghana. Ghana Med J. 2008:42:55-60

7. Adjei GO, Kurtzhals JAL, Rodrigues OP, Alifrangis M, Hoegberg LCG, Kitcher ED, et al. Amodiaquine-artesunate vs artemether-lumefantrine for 
uncomplicated malaria in Ghanaian children: a randomized efficacy and safety trial with one year follow-up. Malar J. 2008;7:127.

8. Oduro AR, Anyorigiya T, Anto F, Amenga-Etego L, Ansah NA, Atobrah P, et al. A randomized, comparative study of supervised and unsupervised artesunate-amodiaquine, for the treatment of uncomplicated malaria in Ghana. Ann Trop Med Parasitol. 2008;102:565-76.

9. Owusu-Agyei S, Asante KP, Owusu R, Adjuik M, Amenga-Etego S, Dosoo DK, et al. An open label, randomised trial of artesunate+amodiaquine, artesunate+chlorproguanil-dapsone and artemether-lumefantrine for the treatment of uncomplicated malaria. PLoS ONE. 2008;3:e2530.

10. Abuaku BK, Mensah BA, Ofori MF, Myers-Hansen J, Derkyi-Kwarteng AN, Essilfie F, et al. Efficacy of artesunate/amodiaquine in the treatment of uncomplicated malaria among children in Ghana. Am J Trop Med Hyg. 2017;97:690-5.

11. Simpson JA, Jamsen KM, Price RN, White NJ, Lindegardh N, Tarning J, et al. Towards optimal design of anti-malarial pharmacokinetic studies. Malar J. 2009;8:189.

12. Barnes Kl, Watkins WM, White NJ. Antimalarial dosing regimens and drug resistance. Trends Parasitol. 2008;24:127-34.

13. Olliaro PL, Mussano P. Amodiaquine for treating malaria. Cochrane Database Syst Rev. 2003;2:CD000016.

14. Zwang J, Olliaro P, Barennes H, Bonnet M, Brasseur P, Bukirwa H, et al. Efficacy of artesunate-amodiaquine for treating uncomplicated falciparum malaria in sub-Saharan Africa: a multi-centre analysis. Malar J. 2009;8:203.

15. Dicko A, Diallo Al, Tembine I, Dicko Y, Dara N, Sidibe Y, et al. Intermittent preventive treatment of malaria provides substantial protection against malaria in children already protected by an insecticide-treated bednet in Mali: a randomised, double-blind, placebo-controlled trial. PLoS Med. 2011;8:e1000407.

16. Ndiaye JL, Cissé B, Ba EH, Gomis JF, Ndour CT, Molez JF, et al. Safety of seasonal malaria chemoprevention (SMC) with sulfadoxine-pyrimethamine plus amodiaquine when delivered to children under 10 years of age by district health services in Senegal: results from a stepped-wedge cluster randomized trial. PLoS ONE. 2016;11:e0162563.

17. Winstanley PA, Simooya O, Kofi-Ekue JM, Walker O, Salako LA, Edwards $\mathrm{G}$, et al. The disposition of amodiaquine in Zambians and Nigerians with malaria. Br J Clin Pharmacol. 1990;29:695-701.

18. Hombhanje FW, Hwaihwanje I, Tsukahara T, Saruwatari J, Nakagawa $\mathrm{M}, \mathrm{Osawa} \mathrm{H}$, et al. The disposition of oral amodiaquine in Papua New Guinean children with falciparum malaria. Br J Clin Pharmacol. 2005;59:298-301.

19. Hietala SF, Bhattarai A, Msellem M, Röshammar D, Ali AS, Strömberg J, et al. Population pharmacokinetics of amodiaquine and desethylamodiaquine in pediatric patients with uncomplicated falciparum malaria. J Pharmacokinet Pharmacodyn. 2007;34:669-86.

20. Adjei GO, Kristensen $\mathrm{K}$, Goka BQ, Hoegberg LCG, Alifrangis M, Rodrigues $\mathrm{OP}$, et al. Effect of concomitant artesunate administration and cytochrome P4502C8 polymorphisms on the pharmacokinetics of amodiaquine in Ghanaian children with uncomplicated malaria. Antimicrob Agents Chemother. 2008;52:4400-6.

21. Stepniewska K, Taylor W, Sirima SB, Ouedraogo EB, Ouedraogo A, Gansané $A$, et al. Population pharmacokinetics of artesunate and amodiaquine in African children. Malar J. 2009;8:200.

22. Mwesigwa J, Parikh S, McGee B, German P, Drysdale T, Kalyango JN, et al. Pharmacokinetics of artemether-lumefantrine and artesunate-amodiaquine in children in Kampala Uganda. Antimicrob Agents Chemother. 2010:54:52-9.

23. Jullien V, Ogutu B, Juma E, Carn G, Obonyo C, Kiechel JR. Population pharmacokinetics and pharmacodynamic considerations of amodiaquine and desethylamodiaquine in Kenyan adults with uncomplicated malaria receiving artesunate-amodiaquine combination therapy. Antimicrob Agents Chemother. 2010;54:2611-7.

24. WHO. Methods and techniques for assessing exposure to antimalarial drugs in clinical field studies: informal consultation organized by the World Health Organization with the technical support of the WorldWide Antimalarial Resistance Network. Geneva: World Health Organization; 2011. https://www.who.int/docs/default-source/documents/publicatio $\mathrm{ns} / \mathrm{gmp} / \mathrm{methods}$-and-techniques-for-assessing-exposure-to-antimalari al-drugs-in-clinical-field-studies.pdf?sfursn=7a2a8c942. Accessed 5 Nov 2020
25. Naisbitt DJ, Ruscoe JE, Williams D, O'Neill PM, Pirmohamed M, Park BK. Disposition of amodiaquine and related antimalarial agents in human neutrophils: implications for drug design. J Pharmacol Exp Ther. 1997;280:884-93.

26. Pussard E, Verdier F, Blayo MC. Simultaneous determination of chloroquine, amodiaquine and their metabolites in human plasma, red blood cells, whole blood and urine by column liquid chromatography. J Chromatogr. 1986;374:111-8.

27. Lindegårdh N, Forslund M, Green MD, Kaneko A, Bergqvist Y. Automated solid-phase extraction for determination of amodiaquine, chloroquine and metabolites in capillary blood on sampling paper by liquid chromatography. Chromatographia. 2002;55:5-12.

28. Gitau EN, Muchohi SN, Ogutu BR, Githiga IM, Kokwaro GO. Selective and sensitive liquid chromatographic assay of amodiaquine and desethylamodiaquine in whole blood spotted on filter paper. J Chromatogr B Analyt Technol Biomed Life Sci. 2004;799:173-7.

29. Winstanley P, Edwards G, Orme M, Breckenridge A. The disposition of amodiaquine in man after oral administration. Br J Clin Pharmacol. 1987:23:1-7.

30. WHO. Methods for surveillance of antimalarial drug efficacy. Geneva, World Health Organization; 2009 http://whqlibdoc.who.int/publicatio ns/2009/9789241597531_eng.pdf. Accessed 5 Nov 2020

31. Plowe CV, Djimde A, Bouare M, Doumbo O, Wellems TE. Pyrimethamine and proguanil resistance-conferring mutations in Plasmodium falciparum dihydrofolate reductase: polymerase chain reaction methods for surveillance in Africa. Am J Trop Med Hyg. 1995;52:565-8.

32. WHO. Methods and techniques for clinical trials on antimalarial drug efficacy: genotyping to identify parasite populations: informal consultation organized by the Medicines for Malaria Venture and cosponsored by the World Health Organization, 29-31 May 2007, Amsterdam, The Netherlands, 2008. http://apps.who.int/iris/bitstream/10665/43824/1/97892 41596305_eng.pdf. Accessed 5 Nov 2020

33. Ranford-Cartwright LC, Taylor J, Umasunthar T, Taylor LH, Babiker HA, Lell B, et al. Molecular analysis of recrudescent parasites in a Plasmodium falciparum drug efficacy trial in Gabon. Trans R Soc Trop Med Hyg. 1997;91:719-24.

34. Food and Drug Administration. Guidance for Industry Bioanalytical Method Validation. 2001. http://www.fda.gov/downloads/Drugs/Guidances/ucm07 0107.pdf. Accessed 5 Nov 2020

35. Carneiro I, Roca-Feltrer A, Griffin JT, Smith L, Tanner M, Schellenberg JA, et al. Age-patterns of malaria vary with severity, transmission intensity and seasonality in sub-Saharan Africa: a systematic review and pooled analysis. PLOS ONE. 2010;5:e8988.

36. WHO. Child growth standards: length/height-for-age, weight-for-age, weight-for-length, weight-for-height and body mass index-for-age; methods and development. Geneva:World Health Organization; 2006. https:// www.who.int/childgrowth/standards/technical_report/en/. Accessed 5 Nov 2020

37. Barnes K, Little F, Smith P, Evans A, Watkins W, White N. Sulfadoxinepyrimethamine pharmacokinetics in malaria: pediatric dosing implications. Clin Pharmacol Ther. 2006;80:582-96.

38. Checchi F, Piola P, Fogg C, Bajunirwe F, Biraro S, Grandesso F, et al. Supervised versus unsupervised antimalarial treatment with six-dose artemether-lumefantrine: pharmacokinetic and dosage-related findings from a clinical trial in Uganda. Malar J. 2006;5:59.

39. Price RN, Hasugian AR, Ratcliff A, Siswantoro H, Purba HLE, Kenangalem $E$, et al. Clinical and pharmacological determinants of the therapeutic response to dihydroartemisinin-piperaquine for drug-resistant malaria. Antimicrob Agents Chemother. 2007;51:4090-7.

40. Ntale M, Obua C, Mukonzo J, Mahindi M, Gustafsson LL, Beck O, et al. Fieldadapted sampling of whole blood to determine the levels of amodiaquine and its metabolite in children with uncomplicated malaria treated with amodiaquine plus artesunate combination. Malar J. 2009;8:52.

41. Bartelink IH, Rademaker CMA, Schobben AFAM, van den Anker JN. Guidelines on paediatric dosing on the basis of developmental physiology and pharmacokinetic considerations. Clin Pharmacokinet. 2006;45:1077-97.

42. Ali AM, Penny MA, Smith TA, Workman L, Sasi P, Adjei GO, et al. Population pharmacokinetics of the antimalarial amodiaquine: a pooled analysis to optimize dosing. Antimicrob Agents Chemother. 2018;62:e02193-e2217.

43. Ding J, Coldiron ME, Assao B, Guindo O, Blessborn D, Winterberg M, et al. Adherence and population pharmacokinetic properties of amodiaquine 
when used for seasonal malaria chemoprevention in African children. Clin Pharmacol Ther. 2020;107:1179-88.

44. Song G, Sun X, Hines RN, McCarver DG, Lake BG, Osimitz TG, et al. Determination of human hepatic CYP2C8 and CYP1A2 age-dependent expression to support human health risk assessment for early ages. Drug Metab Dispos. 2017:45:468-75.

45. Upreti W, Wahlstrom JL. Meta-analysis of hepatic cytochrome P450 ontogeny to underwrite the prediction of pediatric pharmacokinetics using physiologically based pharmacokinetic modeling. J Clin Pharmacol. 2016;56:266-83

46. Orrell C, Little F, Smith P, Folb P, Taylor W, Olliaro P, et al. Pharmacokinetics and tolerability of artesunate and amodiaquine alone and in combination in healthy volunteers. Eur J Clin Pharmacol. 2008;64:683-90.

47. Röwer S, Bienzle U, Weise A, Lambertz U, Forst T, Otchwemah RN, et al. Short communication: high prevalence of the cytochrome $\mathrm{P} 4502 \mathrm{C} 8 * 2$ mutation in Northern Ghana. Trop Med Int Health. 2005;10:1271-3.

48. Kudzi W, Dodoo AN, Mills JJ. Characterisation of CYP2C8, CYP2C9 and CYP2C19 polymorphisms in a Ghanaian population. BMC Med Genet. 2009;10:124

49. Hatton CS, Peto TE, Bunch C, Pasvol G, Russell SJ, Singer CR, et al. Frequency of severe neutropenia associated with amodiaquine prophylaxis against malaria. Lancet. 1986;1:411-4.

50. Neftel KA, Woodtly W, Schmid M, Frick PG, Fehr J. Amodiaquine induced agranulocytosis and liver damage. Br Med J. 1986;292:721-3.

51. Brasseur P, Agnamey P, Gaye O, Cisse M, Badiane M, Vaillant M, et al. Dosing accuracy of artesunate and amodiaquine as treatment for falciparum malaria in Casamance. Senegal Trop Med Int Health. 2009;14:79-87.

52. WorldWide Antimalarial Resistance Network (WWARN) AS-AQ Study Group. The effect of dosing strategies on the therapeutic efficacy of artesunateamodiaquine for uncomplicated malaria: a meta-analysis of individual patient data. BMC Med. 2015;13:66.

53. Allen EN, Mushi AK, Massawe IS, Vestergaard LS, Lemnge M, Staedke SG, et al. How experiences become data: the process of eliciting adverse event, medical history and concomitant medication reports in antimalarial and antiretroviral interaction trials. BMC Med Res Methodol. 2013;13:140.

54. Stepniewska K, Taylor WRJ, Mayxay M, Price R, Smithuis F, Guthmann J-P, et al. In vivo assessment of drug efficacy against Plasmodium falciparum malaria: duration of follow-up. Antimicrob Agents Chemother. 2004;48:4271-80.

55. Lu F, Culleton R, Zhang M, Ramaprasad A, von Seidlein L, Zhou H, et al. Emergence of indigenous artemisinin-resistant Plasmodium falciparum in Africa. N Engl J Med. 2017;376:991-3.

56. Asua V, Vinden J, Conrad MD, Legac J, Kigozi SP, Kamya MR, et al. Changing molecular markers of antimalarial drug sensitivity across Uganda. Antimicrob Agents Chemother. 2019;63:e01818-e1918.

57. Uwimana A, Legrand E, Stokes BH, et al. Emergence and clonal expansion of in vitro artemisinin-resistant Plasmodium falciparum kelch13 R561H mutant parasites in Rwanda. Nat Med. 2020;26:1602-8.

58. Churchill FC, Patchen LC, Campbell CC, Schwartz IK, Nguyen-Dinh P, Dickinson CM. Amodiaquine as a prodrug: importance of metabolite(s) in the antimalarial effect of amodiaquine in humans. Life Sci. 1985;36:53-62.
59. Parikh S, Ouedraogo J-B, Goldstein JA, Rosenthal PJ, Kroetz DL. Amodiaquine metabolism is impaired by common polymorphisms in CYP2C8: implications for malaria treatment in Africa. Clin Pharmacol Ther. 2007;82:197-203.

60. White NJ, Stepniewska K, Barnes K, Price RN, Simpson J. Simplified antimalarial therapeutic monitoring: using the day-7 drug level? Trends Parasitol. 2008;24:159-63.

61. Omole MK, Onademuren OT. A survey of antimalarial drug use practices among urban dwellers in Abeokuta Nigeria. Afr J Biomed Res. 2010;13:1-7.

62. WHO. Levels and trends in child malnutrition. UNICEF/WHO/World Bank Group Joint Child Malnutrition Estimates. Key findings of the 2019 edition. https://www.who.int/nutgrowthdb/jme-2019-key-findings.pdf?ua=1. Accessed 5 Nov 2020.

63. WorldWide Antimalarial Resistance Network (WWARN) Lumefantrine PK/PD Study Group. Artemether-lumefantrine treatment of uncomplicated Plasmodium falciparum malaria: a systematic review and meta-analysis of day 7 lumefantrine concentrations and therapeutic response using individual patient data. BMC Med. 2015;18:227. Erratum in: BMC Med. 2016;14 (1):214

64. Chotsiri P, Denoeud-Ndam L, Baudin E, Guindo O, Diawara H, Attaher O, et al. Severe acute malnutrition results in lower lumefantrine exposure in children treated with artemether-lumefantrine for uncomplicated malaria. Clin Pharmacol Ther. 2019;106:1299-309.

65. Fitoussi S, Thang C, Lesauvage E, Barré J, Charron B, Filali-Ansary A, Lameyre V. Bioavailability of a co-formulated combination of amodiaquine and artesunate under fed and fasted conditions. A randomised, open-label crossover study. Arzneimittelforschung. 2009;59:370-6.

66. Olawoye OS, Adeagbo BA, Bolaji OO. Moringa oleifera leaf powder alters the pharmacokinetics of amodiaquine in healthy human volunteers. J Clin Pharm Ther. 2018;43:626-32.

67. Yasuda SU, Zhang L, Huang S-M. The role of ethnicity in variability in response to drugs: focus on clinical pharmacology studies. Clin Pharmacol Ther. 2008:84:417-23.

68. Kerb R, Fux R, Mörike K, Kremsner PG, Gil JP, Gleiter CH, et al. Pharmacogenetics of antimalarial drugs: effect on metabolism and transport. Lancet Infect Dis. 2009;9:760-74.

69. Medicines for Malaria Venture. 81-million-courses-seasonal-malariachemoprevention-delivered-countries. https://www.mmv.org/our-impact/ achievements/96-million-courses-seasonal-malaria-chemoprevention-deliv ered-13-countries. Accessed 5 Nov 2020

70. World Medical Association. Declaration of Helsinki - Ethical Principles of Medical Research Involving Human Subjects 2013. https://www.wma.net/ policies-post/wma-declaration-of-helsinki-ethical-principles-for-medic al-research-involving-human-subjects/. Accessed 5 Nov 2020.

71. International conference on harmonisation of technical requirements for registration of pharmaceuticals for human use. ICH harmonised tripartite guideline. Guideline for good clinical practice, E6(R1) 1997. https://ichgc p.net. Accessed 5 Nov 2020.

\section{Publisher's Note}

Springer Nature remains neutral with regard to jurisdictional claims in published maps and institutional affiliations.

\footnotetext{
Ready to submit your research? Choose BMC and benefit from:

- fast, convenient online submission

- thorough peer review by experienced researchers in your field

- rapid publication on acceptance

- support for research data, including large and complex data types

- gold Open Access which fosters wider collaboration and increased citations

- maximum visibility for your research: over $100 \mathrm{M}$ website views per year
}

At BMC, research is always in progress.

Learn more biomedcentral.com/submissions 